\title{
A Review on Comparison of Tooth Size Discrepancies among Angle's Class I, II, and III Malocclusion: Is There a Significance?
}

\author{
Mehjabeen A Jabri ${ }^{1}$, Song $\mathrm{Wu}^{2}$, Yaoyuan Zhang ${ }^{3}$, Junqing $\mathrm{Ma}^{4}$, Lin Wang ${ }^{5}$
}

\begin{abstract}
Aim: The contemporary article aims to review and compare various literatures concerning different conclusions regarding the correlation between tooth size discrepancy (TSD) and Angle's malocclusion groups.

Background: Acquiring the ideal occlusion plays one of the major roles while designing the treatment plan for an orthodontic patient, any alterations in the individual tooth sizes are called TSD and will hinder this prime requirement. By determining the correct tooth size ratio, it further helps in acquiring the accurate interdigitation, balanced occlusion, and also predicting the orthodontic treatment results. Various investigations were carried out to know the correlation between tooth size discrepancies and different malocclusion groups, of which, a few reported a statistically significant difference whereas others reported no significant difference.

Review results: A computerized database quest was operated utilizing the Medline database (Pubmed/Medline) for original research and review articles. Publications between 1946 and 2018 were included. Four hundred twenty-one articles were recovered from database search and, among them, 66 articles were selected to review the full-article.

Conclusion: Although a comparison was done between the tooth-size ratios and malocclusion groups (classes I, II, and III), many investigators noted no significant difference but there is an inadequacy in the data particularly related to subgroups of Angle's classification of malocclusion among these investigations; therefore, further studies are required to interpret this correlation.

Clinical significance: As there is high incidence of tooth size discrepancies noted in the previous literature orthodontist, Bolton's analysis regardless of malocclusion group, sex, and ethnicity is highly recommended.

Keywords: Angle class I, Angle class II, Angle class III, Malocclusion, Mandible, Maxilla, Orthodontics.

The Journal of Contemporary Dental Practice (2019): 10.5005/jp-journals-10024-2615
\end{abstract}

\section{INTRODUCTION}

Tooth size widths may vary in different groups of malocclusion as a result interfering in designing the accurate treatment plan and acquiring the best treatment results. This article aims to review and compare various literatures concerning different conclusions regarding the correlation between TSD and Angle's malocclusion groups. An extensive diagnosis, treatment strategy, and analyzing the data accurately are the prime requirements for obtaining the best treatment results, which are functionally and esthetically desirable at the termination of the orthodontic treatment. Among various factors that play an important role in acquiring successful treatment results, one of the prime factors is individual tooth sizes. Achievement of balanced occlusion, interdigitation, and forecasting the treatment results can be done by identifying the tooth size ratios. ${ }^{1}$ Asymmetry among the sizes of respective teeth can be defined as TSD. The first person to correctly examine the mesiodistal widths of the teeth was Black. ${ }^{2}$ In 1958, Bolton ${ }^{3}$ proposed the firstrate investigation of TSD for correction of malocclusion. In 1972, the six keys of occlusion were first proposed by Andrews in his study conducted among nonorthodontic patients. It was later that McLaughlin et al. ${ }^{4}$ joined equitable tooth size as the seventh key. In the concluding phase of orthodontic treatment, it is important to achieve the correct occlusal interdigitation for which appropriate maxillary and the mandibular mesiodistal tooth-size relationship is of utmost importance. The inter-relationship between tooth size discrepancies and various malocclusion groups was investigated by many studies, of which, a few proclaimed no significance and a few $\overline{{ }^{1-5} \text { Department of Orthodontics, The Stomatological Hospital of }}$ Jiangsu Province affiliated to Nanjing Medical University, Jiangsu Key Laboratory of Oral Diseases, Nanjing, China

Corresponding Author: Lin Wang, Department of Orthodontics, The Stomatological Hospital of Jiangsu Province affiliated to Nanjing Medical University, Jiangsu Key Laboratory of Oral Diseases, Nanjing, China, Phone: +86-025-85031885, e-mail: Iw603@njmu.edu.cn

How to cite this article: Jabri MA, Wu S, et al. A Review on Comparison of Tooth Size Discrepancies among Angle's Class I, II, and III Malocclusion: Is There a Significance? J Contemp Dent Pract 2019;20(8):994-999.

Source of support: The Priority Academic Program Development of Jiangsu Higher Education Institutions (PAPD-2018-87) and The Jiangsu Provincial Key Medical Discipline (ZDXKA2016026).

Conflict of interest: None

proclaimed significance. ${ }^{5,6}$ According tofew investigators, ethnicity also plays a role in the variation of tooth-size ratios. Reports of the previous studies reveal that individuals of Caucasian ethnic background have smaller teeth compared to African individuals. ${ }^{25}$ And, a few other studies reported that Bolton's value is not relevant to Japanese or Turkish population. ${ }^{7,8}$ The objective of the present study is to review the literature in relation to the correlation between tooth size discrepancies and Angle's malocclusion.

\section{Search Strategy}

To analyze and systemize applicable data related to tooth-size discrepancies observed in various Angle's malocclusion groups, a 
computerized database quest was operated utilizing the Medline database (Pubmed/Medline) for original research and review articles. Publications between 1946 and 2018 were included. The terms included in search were "tooth-size discrepancies" in conjugation with "Bolton's analysis," "Angle's malocclusion," "Class I, II, and III malocclusion," "Orthodontic treatment," and "diagnosis." Four hundred twenty-one articles were recovered from database search and, among them, 66 articles were selected to review the fullarticle and data from 40 articles of 66 articles were compiled in the review. The inclusion criteria were to retrieve full-text pdf on articles based on original research, systematic reviews, and literature reviews on comparison between TSD and various malocclusion groups, whereas the exclusion criteria were not to retrieve articles based on the case studies and short communications.

To select the full articles from abstracts, inclusion criteria were designed such as the subjects had to be patients seeking orthodontic treatment, patients with Angle's class I, II, and III malocclusion, growing patients, without any pathologic alterations in tooth morphology, eruption of dentition in oral cavity, and human-controlled clinical trials. Exclusion criteria were subjects with normal occlusion, subjects with subclass of Angle's malocclusion group, subjects with congenital absences of dentition or other tooth anomalies. The articles with no abstract available but proposed an accord to the objectives of contemporary review were also selected to evaluate the full text. Further applicable publications were also hand searched among the reference list of retrieved articles that could have been unnoticed in the database. Two reviewers independently reviewed the contemporary literature review.

\section{What is Tooth-size Discrepancy?}

To achieve proper diagnosis and to design a successful treatment plan for an orthodontic patient, the ratio of maxillary and mandibular tooth-sizes plays an important role. In a previous literature, the emphasis on tooth-size discrepancy has been extensively noted and recognized by orthodontists as a significant diagnostic element for relating maxillary and mandibular arches. Whether the treatment plan demands the extraction of teeth or not can be judged by analyzing tooth-size discrepancies before the commencement of orthodontic treatment. ${ }^{9}$ Principally, the mesiodistal width of the tooth is termed as the tooth size. It is not proper to achieve proper occlusion if there is a single or multiple tooth-size discrepancies along the arch. ${ }^{10}$ Following Black's investigation of tooth width, various other authors attempted to inspect tooth widths like Neff ${ }^{11}$ and Lundstrom. ${ }^{12}$ But Bolton's ${ }^{3}$ work was utmost accepted. According to his reports, $29 \%$ of the patients showed tooth-size discrepancies greater than $\pm 1 S D$ in his exclusive clinic and Richardson and Malhotra ${ }^{37}$ revealed analogous discrepancies among $33.7 \%$ patients in their reports. According to Crossby and Alexander, ${ }^{5}$ tooth-size discrepancies must be greater than \pm 2 SD to affect orthodontic treatment and $22.9 \%$ of patients anterior ratios were significantly diverted from the mean of Bolton's analysis in their study. The investigation of Crossby and Alexander was further fortified by other investigators by finding discrepancy greater than $\pm 2 S D$ in $28 \%$ of the Dominican population. ${ }^{13}$ In Bolton's investigation, he selected a small, homogenous, and untreated group which included 55 participants with the finest occlusion but only females, out of which, there were 44 orthodontically treated cases without extractions and untreated cases were 11. "Bolton's overall ratio" was estimated as the ratio of aggregated mesiodistal widths of 12 mandibular teeth to 12 maxillary teeth. By performing the comparison of aggregated mesiodistal widths, six mandibular anterior teeth to six maxillary posterior teeth, "Bolton's anterior ratio" was calculated. So, for achieving the maximum intercuspation between maxillary and mandibular dentition, an overall ratio of 91.3 and the anterior ratio of 77.2 were needed as determined by Bolton's. ${ }^{3}$ For the estimation of the esthetic and functional result of treatment, Bolton's overall ratio and the anterior ratio can be utilized.

Bolton's overall ratio was calculated by utilizing the subsequent formula.

$$
\text { Overall ratio }=\frac{\text { Sum of mandibular } 12}{\text { Sum of maxillary } 12} \times 100=91.3 \%
$$

For overall ratio $=91.3 \%$ the SD is $1.91 \%$.

If the ratio is lesser than $91.3 \%$, it indicates maxillary tooth material excess and can be calculated by the following formula:

Excess maxillary $12=$ sum of maxillary 12

$$
-\frac{\text { sum of mandibular } 12}{91.3} \times 100
$$

If the ratio is greater than $91.3 \%$, it indicates mandibular tooth material excess and can be calculated by the following formula

$$
\begin{aligned}
\text { Excess mandibular } 12= & \text { sum of mandibular } 12 \\
& -\frac{\text { sum of maxillary } 12}{91.3} \times 100
\end{aligned}
$$

Bolton's anterior ratio was calculated by utilizing the subsequent formula.

$$
\text { Anterior ratio }=\frac{\text { Sum of mandibular } 6}{\text { Sum of maxillary } 6} \times 100=77.2 \%
$$

For anterior ratio $=77.2 \%$ the SD is $1.65 \%$.

If the ratio is lesser than $77.2 \%$, it indicates maxillary anterior tooth material excess that can be calculated as

$$
\begin{aligned}
\text { Excess maxillary } 6= & \text { sum of maxillary } 6 \\
& -\frac{\text { sum of mandibular } 6}{77.2} \times 100
\end{aligned}
$$

If the ratio is greater than $77.2 \%$, it indicates mandibular anterior tooth material excess that can be calculated as

$$
\begin{aligned}
\text { Excess mandibular } 6= & \text { sum of mandibular } 6 \\
& -\frac{\text { sum of maxillary } 6}{77.2} \times 100
\end{aligned}
$$

Although Bolton's anterior ratio and the overall ratio are being highly utilized in contemporary orthodontics, it also has many limitations such as it neglects the consequence of incisors thickness, tip of incisors, interincisor angle, overjet, and overbite on the correlation in between the respective teeth. ${ }^{13}$

\section{What is Angle's Malocclusion?}

Both maxillary and mandibular dental arches are the fundamental units of the masticatory complex. Any discrepancy in the relationship between maxillary and mandibular dental arches is called as malocclusion and is of prime concern to both clinical and biological aspects. ${ }^{14,15}$ Consequently, for appropriate action to 
take place in articulation, mastication, and respiration, the proper spatial adjustment of dental arches plays an important role. ${ }^{16,}$ ${ }^{17}$ It is believed that environmental and/or genetic factors cause malocclusions which in turn promotes aberrant contact between the units of the facial complex such as hard and soft tissues. ${ }^{18}$ To investigate and understand the vast array observed between the dental arches, there is a broad frame of literature addressing malocclusion. ${ }^{19-22}$ Various orthodontist have promoted methods of classification, among them, the Angle ${ }^{23}$ method is by far the most widely accepted and commonly used classification to clinically explain the relationship between maxillary and mandibular teeth in occlusion which was developed a century ago. In his investigation, he stated that when the teeth are in occlusion, on the bases of anterioposterior (mesiodistal) relationship of maxillary and mandibular lower first permanent molars, three categories could be precisely designated to the jaws and dental arches. His data included school children of St. Louis, Missouri, and were 1,000 in number; according to his investigation, all children who were included in his study exhibited malocclusion and grouped them according to the malocclusion classification. Among the 1,000 school children, 692 were categorized into the class I group, 40 werecategorized into the class II division 1 group, 34 were categorized into the class II division 1 subdivision (unilateral) group, 42 were categorized into the class II division 2 group, 100 were categorized into the class II division 2 subdivision group, 34 were categorized into the class III group, and 8 were categorized into the class III subdivision group.

If maxilla and mandible exhibit proper anterioposterior relationship, it is defined as class I normal occlusion with the alignment of teeth over the occlusion line in a trajectory curve in which there is a $2 \mathrm{~mm}$ overlap in horizontal and vertical planes of upper incisors on lower incisors. According to Proffit, ${ }^{24}$ class I normal occlusion is present in $30 \%$ of the US population. If there is an improper position of the individual particular teeth along the occlusion line, it is termed as class I malocclusion and it exists in $50-50 \%$ of the US population. Nevertheless, the maxilla-mandibular relationship is alike as normal occlusion. If the facial profile is convex and anterioposterior overlap of maxillary anterior incisors is more than $2 \mathrm{~mm}$, it is noted as class II malocclusion and it is found in $15 \%$ of the US population. Lastly, if the facial profile is concave and mandibular teeth are positioned forward when compared with maxillary teeth, it is termed as class III malocclusion and it affects $1 \%$ of the US population. It becomes more difficult for a clinician to carry out the treatment plan further if there is a coexistence of intra-arch or inter-arch irregularities in these malocclusion types (Table 1). ${ }^{24}$

\section{Review of Literature on the Correlation between Tooth Size Discrepancies and Angle's Class I, II, and III Malocclusion}

TSD ratio can be used to obtain an understanding of the aesthetic and functional outcome of a particular case without utilizing the diagnostic setup. The most commonly used method for predicting the inter-arch TSD is Bolton's analysis because of its accuracy, ease, and requires lesser time to record the measurements. To state the difference in tooth sizes among the different sexes, racial and ethnic groups have been pursued by many studies but the difference between discrete occlusion class and difference among genders are two main categories which are most enlightening. ${ }^{25,26}$ It has been reported in different literatures that sex differences can be clinically relevant. Deciduous dentition shows lesser sex difference
Table 1: List of studies which shows a statistically significant difference in correlation between the TSD and various malocclusion groups in different population

\begin{tabular}{lll}
\hline Study & Population & Significant difference \\
\hline Araujo $^{9}$ & Brazilian & Yes $^{\mathrm{a}}$ \\
Fattahi $^{38}$ & Iranian & Yes $^{\mathrm{b}}$ \\
$\mathrm{Ni}^{43}$ & Chinese & Yes $^{\mathrm{c}}$ \\
$\mathrm{Ta}^{1}$ & Southern Chinese & Yes $^{\mathrm{d}}$ \\
\hline
\end{tabular}

The significantly greater prevalence of TSD was observed in subjects with classes I and III than with class II

${ }^{\mathrm{b}} \mathrm{A}$ statistically significant difference was found only for the mean anterior ratio but not for the overall ratio

'The results revealed the significant difference for both anterior and overall ratio showing that class III > class I > class II

${ }^{d}$ Class III occlusion group showed statistically significant difference with the Bolton standard for anterior ratio, statistically significant difference wasfound between classes II and III occlusion groups and between the Bolton standard and the class II occlusion group for the overall ratio

when compared with permanent dentition as reported by Seipel. ${ }^{27}$ Usually, women's teeth are identified smaller than men's teeth. The maxillary lateral incisors and mandibular central incisors are almost homologous. ${ }^{28,29}$ Whereas, the greatest sex difference is identified among maxillary central incisors and canines in both permanent and deciduous dentitions. ${ }^{30,31}$ In between maxillary and mandibular anterior teeth tooth-size proportions, there is an inadequate compliance regarding sex differences. ${ }^{9,26,37,41}$ According to the study carried out by Samseshima, ${ }^{32}$ no significant difference was noted among ethnic groups or sexes in subjects exhibiting greater than 2SD, but the overall tooth-size ratio of Asians and Hispanics was significantly smaller than Africans. According to Bolton, ${ }^{3}$ in his study, there are no recorded data describing the other racial and ethnic groups because his study is only based on the heterogeneous Caucasian sample. According to studies of Smith et al. ${ }^{25}$ and Lavelle, ${ }^{26}$ it was recorded that various ethnic and racial groups show the difference in TSD. In Lavelle's ${ }^{26}$ study, the different racial and ethnic groups included to investigate tooth-size ratio were Caucasian, Mongoloid, and Blacks and there was a noted significant difference among Blacks and Mongoloid although, the Mongoloid race had the intermediate overall and anterior ratio when compared to the Black race which had the highest followed by the Caucasian race. The difference in tooth size among males and females was investigated by Richardson and Malhotra ${ }^{37}$ in a sample of North American population and stated that tooth sizes of males were larger than tooth sizes of females for every tooth in the maxillary and the mandibular arch. According to the investigation done by Smith et al. ${ }^{25}$ Bolton's ratio was smaller for females than males. Among the various malocclusion groups, the standard deviations of Bolton's were lesser than the standard deviations of intermaxillary tooth size ratios, even if intermaxillary tooth size ratios were proportionate to Bolton's means as noted by Crossby and Alexander, ${ }^{5}$ their study contained subjects which were orthodontically treated patients of various malocclusion groups (class I and II division 2 and class III surgically treated). Currently, a correlation between malocclusion groups and tooth-size discrepancies was noted. In an investigation carried out by Lavelle, ${ }^{26}$ it was reported that subjects for anterior tooth sizes revealed inclinations for patients with Angle class I and II malocclusion to have larger maxillary teeth when compared with patients having Angle class III malocclusion. According to his study, mandibular 
teeth was comparatively smaller in class I and II subjects than class III subjects, with the conflict that class III subjects revealed greater Bolton's discrepancy compared to other malocclusion groups. According to a study which investigated the prevalence toothsize discrepancy among malocclusion groups by Sperry et al. ${ }^{33}$ revealed that class I and II subjects showed lesser mandibular tooth-size excess compared to than did the class III subjects. No significant difference was noted for tooth-size discrepancies among malocclusion groups and a normal occlusion group by Xia and $\mathrm{Wu}^{34}$ whereas another study carried out by Qiong and Jiuxiang ${ }^{35}$ recorded a propensity regarding Bolton's discrepancy class II and III malocclusion subjects when they compare five malocclusion groups that recorded no statistical significant difference among the groups. Cua-Benward et al. ${ }^{36}$ investigated the predominance of missing teeth in different malocclusion groups and noted a higher predominance of maxillary tooth malformations in the class III and II malocclusion groups had more mandibular tooth deformities. Concordance to the study carried out by Fattahi et al., ${ }^{38}$ the overall ratio of the whole sample revealed no significant difference statistically but the mean anterior ratio (79.01) showed the significant difference when compared to Bolton's (77.20). There was no statistically significant difference among Angle's class I, II, and III malocclusion groups on comparing the anterior and overall Bolton's ratio in the investigation reported by Lopatiene. ${ }^{39}$ Also, a study carried out by Toshiya et al. ${ }^{40}$ disclosed that overall and anterior ratios among various malocclusion group had no significant difference. An investigation was done in 2006 by Al Khateeb and Abu Alhaija ${ }^{41}$ revealed that Bolton's ratio showed no significant difference among various malocclusion groups. The mean anterior ratio of class II $(p<0.01)$ cases was found to be significantly greater as reported by Batool et al. ${ }^{42}$ in his report. In a study carried out in the Chinese population by Nie and Lin, ${ }^{43}$ the malocclusion groups in which the mean value of class II group was lower than class I and III groups (class II < class I < class III) had a significant difference in tooth-size ratios. There was a study conducted among the Saudi population by Hashim and Murshid ${ }^{44}$ in which subjects were taken within the age range of 13-20 years who had different types of malocclusion and the intermaxillary tooth-size ratio was measured, the results revealed no significant difference when Bolton's mean was compared with the mean of anterior and overall tooth-size ratio. There was no significant difference in the results of a study done by Basaran et al. ${ }^{45}$ on pre-treatment models of patients without any malocclusion and also he had done a comparison investigation between different malocclusion groups and revealed that there was no significant difference.

In the study carried out by Uysal et al., ${ }^{46}$ various malocclusion groups were included like Angle's class I group, class II division 1 group, class II division 2 group, and class III group; his prime motive was to investigate the difference between tooth-size ratios of male and female individuals for overall and anterior ratios and then he found that there is a significant sex difference in individuals with normal occlusion $(p<0.001)$ in the overall ratio but not anterior ratio and different malocclusion groups showed no statistically significant difference. According to a study done on Yemani population among different malocclusion groups, the mesiodistal tooth widths between right and left sides revealed no statistically significant difference. A few studies also reported the same results but done on different populations like Saudis by Murshid and Hashim ${ }^{47}$ and Jordaniansby Hattab et al. ${ }^{48}$ But the aforementioned conclusion does not support the investigation which revealed that there is a significant difference in tooth-size ratios between right and left sides. ${ }^{49}$ In a study done by Ghose and Baghdady, ${ }^{50}$ data fromthree groups collected from the regions of Arabian Peninsula and tooth size of Yemenis, Bedouins and Iraqis were compared and they found that there is a significant increase in tooth size width from south to north Iraqis who had the largest tooth size, followed by Bedouins and Iraqis. Assessment of correlation amongclass I, II, III, and TSD in the anterior region among 300 Brazilian patients was investigated by Araujo and Souki ${ }^{9}$ and their results revealed that patients with the class II malocclusion group exhibited a lower tendency of TSD in the anterior region when compared with patients with class I and III malocclusion groups. In another study done with 711 Brazilian patients, all the Angle's malocclusion groups like class I, class II, and class III showed no statistically significant difference in both overall and anterior ratios. ${ }^{51} \mathrm{~A}$ few investigators assessed the possible correlation between the three arch forms (square, ovoid, and tapered) and tooth-size discrepancy in the Saudi population, the results revealed no association between the Bolton discrepancy and the arch form. ${ }^{52}$ Finally, it is essential to consider that besides other important components such as skeletal component, soft tissue component, and other dental and skeletal evaluation factors of orthodontic treatment planning system, toothsize discrepancies evaluation is only an element of this system. Tooth-size discrepancies should be analyzed and focused at the same time when considering the other treatment problems. The ultimate treatment plan and results are best analyzed as essential parts, not the specific components in particular (Table 2).

\section{ConCLUSion}

On comparison of tooth-size ratios as a function of sex and ethnic groups, many investigations have been listed in the dental literature but most of them found no significant difference. Although a comparison was done between the tooth-size ratios and malocclusion groups (class I, II, and III), many investigators noted no significant difference but there is an inadequacy in the data particularly related to subgroups of Angle's classification of malocclusion among these investigations; therefore, further studies

Table 2: List of studies which shows no statistically significant difference in correlation between the TSD and various malocclusion groups in different population

\begin{tabular}{lll}
\hline Study & Population significant & Difference \\
\hline Alkyalçin $^{53}$ & Turkish & $\mathrm{No}^{\mathrm{a}}$ \\
Al-Khateeb $^{41}$ & Jordanian & $\mathrm{No}^{\mathrm{b}}$ \\
Crossby $^{5}$ & American & $\mathrm{No}^{\mathrm{c}}$ \\
Uysal $^{46}$ & Turkish & $\mathrm{No}^{\mathrm{d}}$ \\
Basaran $^{45}$ & Turkish & $\mathrm{No}^{\mathrm{e}}$ \\
John $^{54}$ & 3 groups $^{\mathrm{f}}$ & $\mathrm{No}$ \\
\hline
\end{tabular}

aThe mean values for Bolton's overall and anterior ratios between malocclusion groups and sexes revealed no statistically significant difference

${ }^{b}$ Among the different malocclusion groups, no statistically significant difference was revealed

'There was no statistically significant difference acquired in results on comparing the different malocclusion groups and tooth size discrepancies ${ }^{\mathrm{d}}$ Among the different malocclusion groups, there was a statistically significant difference found

eNo significant difference was found for overall and anterior ratios between the various malocclusion groups

fThe study was conducted on subjects from three different ethnic backgrounds such as Caucasians, Hispanics, and African-Americans 
are required to interpret this correlation. Therefore, the orthodontist should be receptive of this high incidence of discrepancies while diagnosing and designing the treatment plant for the patients looking for the orthodontic treatment. Hence, routinely performing Bolton's analysis regardless of the malocclusion group, sex, and ethnicity is highly recommended.

\section{References}

1. Al-Gunaid T, Yamaki M, et al. Mesiodistal tooth width and tooth size discrepancies of Yemeni Arabians: A pilot study. J Ortho Sci 2012 Apr;1(2):40-45. DOI: 10.4103/2278-0203.99760.

2. Black GV. Descriptive Anatomy of the Human Teeth. Philadelphia: S.S. White Dental Mfg. Co; 1902.

3. Bolton WA. Disharmony in tooth size and its relation to the analysis and treatment of malocclusion. Angle 1958;28(3):113-130.

4. McLaughlin RP, Bennett JC, et al. Systemized Orthodontic Treatment Mechanics. London: Mosby.; 2001. pp. 4, 6, 281.

5. Crossby DR, Alexander CG. The occurrence of tooth size discrepancies among different malocclusion groups. Am J Orthod Dentofacial Orthop 1989 Jun;95(6):457-461. DOI: 10.1016/0889-5406(89)90408-3.

6. Ta TA, Ling JY, et al. Tooth-size discrepancies among different occlusion groups of southern Chinese children. Am J Orthod Dentofacial Orthop 2001 Nov;120(5):556-558. DOI: 10.1067/ mod.2001.118998.

7. Uysal T, Sari Z. Intermaxillary tooth size discrepancy and mesiodistal crown dimensions for a Turkish population. Am J Orthod Dentofacial Orthop 2005 Aug;128(2):226-230. DOI: 10.1016/j.ajodo.2004.04.029.

8. Endo T, Shundo I, et al. Applicability of Bolton's tooth size ratios to a Japanese orthodontic population. Odontology 2007 Jul;95(1):57-60. DOI: 10.1007/s10266-007-0066-8.

9. Aaraujo E, Souki M. Bolton anterior tooth size discrepancies among different malocclusion groups. Angle Orthod 2003 Jun;73(3):307-313.

10. Prasanna AL, Venkatramana V, et al. Evaluation and Comparison of Intermaxillary Tooth Size Discrepancy among Class I, Class II Division 1, and Class III Subjects Using Bolton's Analysis: An in vitro Study. J Int Oral Health 2015 Sep;7(9):58-64.

11. Neff CW. The size relationship between the maxillary and mandibular anterior segments of the dental arch. Angle Orthodontist 1957;27(3):138-147.

12. Lunstrom A. Intermaxillary tooth width ratio and tooth alignment and occlusion. Acta Odontol Scand 1955 Feb;12(3-4):265-292. DOI: 10.3109/00016355509028167.

13. Hasija N, Bala M, et al. Estimation of Tooth Size Discrepancies among Different Malocclusion Groups. Int J Clin Pediatr Dent 2014 May;7(2):82-85. DOI: 10.5005/jp-journals-10005-1242.

14. Bernabé E, Major PW, et al. Tooth-width ratio discrepancies in a sample of Peruvian adolescents. Am J Orthod Dentofacial Orthop 2004;125(3):361-365. DOI: 10.1016/j.ajodo.2003.04.008.

15. Ackerman JL, Profitt WR, et al. Pitch, roll, and yaw: describing the spatial orientation of dentofacial traits. Am J Orthod Dentofacial Orthop 2007 Mar;131(3):305-310. DOI: 10.1016/j.ajodo.2006.05.032.

16. Miller SF, Vela KC, et al. Patterns of morphological integration in the dental arches of individuals with malocclusion. Am J Hum Biol 2016 Nov;28(6):879-889. DOI: 10.1002/ajhb.22880.

17. Howel PG. Incisal relationships during speech. J Prosthet Dent 1986 Jul;56(1):93-99. DOI: 10.1016/0022-3913(86)90289-1.

18. Singh GD. Morphologic determinants in the etiology of class III malocclusions: a review. Clin Anat 1999;12(5):382-405. DOI: 10.1002/ (SICI)1098-2353(1999)12:5<382::AID-CA9>3.0.CO;2-0.

19. Ruf S, Pancherz H. Class II Division 2 malocclusion:genetics or environment? A case report of monozygotic twins. Angle Orthod 1999 Aug;69(4):321-324. DOI: 10.1043/0003-3219(1999)069<0321:CID $\mathrm{MGO}>2.3 . \mathrm{CO} ; 2$.

20. Basdra EK, Kiokpasoglou M, et al. The Class II Division 2 craniofacial type is associated with numerous congenital tooth anomalies. Eur J Orthod 2000 Oct;22(5):529-535. DOI: 10.1093/ejo/22.5.529.
21. Xue F, Wong RW, et al. Genes, genetics, and Class III malocclusion. Orthod Craniofac Res 2010 May;13(2):69-74. DOI: 10.1111/j.16016343.2010.01485.x.

22. Baccetti T, Reyes BC, et al. Gender differences in Class III malocclusion. Angle Orthod 2005;75(4):510-520.

23. Angle EH. Treatment of malocclusion of the teeth and fractures of the maxillae; Angle's system, 6th ed. Philadelphia: SS White Manufacturing; 1900, pp. 37-44, vol. 6-8.

24. Proffit WR, Fields Jr HW, et al. Prevalence of malocclusion and orthodontic treatment need in the United States: estimates from the NHANES III survey. Int J Adult Orthodon Orthognath Surg 1998;13(2):97-106.

25. Smith SS, Buschang PH, et al. Interarch tooth size relationships of 3 populations:"does Bolton's analysis apply?". Am J Orthod Dentofacial Orthop 2000 Feb;117(2):169-174. DOI: 10.1016/S0889-5406(00) 70228-9.

26. Lavelle CL. Maxillary and mandibular tooth size in different racial groups and in different occlusal categories. Am J Orthod 1972 Jan;61(1):29-37. DOI: 10.1016/0002-9416(72)90173-X.

27. Seipel C. Variation in tooth position, A metric study of variation and adaption in the deciduous and permanent dentitions. Swed Dent J 1946;39:1-176.

28. Potter $\mathrm{RH}$. Univariate vs multivariate differences in tooth size according to sex. J Dent Res 1972 May-Jun;51(3):716-722. DOI: 10.1177/00220345720510030501.

29. Arya BS, Savara BS, et al. Relation of sex and occlusion to mesiodistal tooth size. Am J Orthod 1974 Nov;66(5):479-486. DOI: 10.1016/00029416(74)90109-2.

30. Doris JM, Bernard BW, et al. A biometric study of tooth size and dental crowding. Am J Orthod 1981 Mar;79(3):326-336. DOI: 10.1016/00029416(81)90080-4.

31. Othman S, Harradine N. Tooth size discrepancies in an orthodontic population. Angle Orthod 2007 Jul;77(4):668-674. DOI: 10.2319/031406-102.

32. Sameshima GT. Bolton tooth size variation among four ethnic groups. Eur J Orthod 2006;45:234-250.

33. Sperry TP, Worms FW, et al. Tooth-size discrepancy in mandibular prognathism. Am J Orthod 1977 Aug;72(2):183-190. DOI: 10.1016/00029416(77)90059-8.

34. Xia Z, Wu XY. The application of dentocclusal measurement in malocclusion. Stomatology 1983;3:126-127.

35. Qiaong N, Jiuxiang L. Comparison of intermaxillary tooth size discrepancies among different malocclusion groups. Am J Orthod Dentofacial Orthop 1999;116:539-554. DOI: 10.1016/S08895406(99)70186-1.

36. Cua-Benward GB, Dibaj S, et al. The prevalance of congenitally missing teeth in Class I, Class II, Class III malocclusions. J Clin Pediatr Dent 1992;17:15-17.

37. Richardson ER, Malhotra SK. Mesiodistal crown dimension of the permanent dentition of American Negroes. Am J Orthod 1975 Aug;68(2):157-164. DOI: 10.1016/0002-9416(75)90204-3.

38. Fattahi HR, Pakshir HR, et al. Comparison of tooth size discrepancies among different malocclusion groups. Eur J Orthod 2006 Oct;28(5):491-495. DOI: 10.1093/ejo/cjl012.

39. Lopatiene K, Dumbravaite A. Relationship between tooth size discrepancies and malocclusion. Stomatologija 2009;11(4):119-124.

40. Endo T, Abe R, et al. Tooth size discrepancies among different malocclusions in a Japanese orthodontic population. Angle Orthod 2008 Nov;78(6):994-999. DOI: 10.2319/101007-486.1.

41. Al-Khateeb SN, Abu Alhaija ES. Tooth size discrepancies and arch parameters among different malocclusions in a Jordanian sample. Angle Orthod 2006 May;76(3):459-465. DOI: 10.1043/00033219(2006)076[0459:TSDAAP]2.0.CO;2.

42. Batool I, Abbas A, et al. Evaluation of tooth size discrepancy in different malocclusion groups. J Ayub Med Coll Abbottabad 2008 Oct-Dec;20(4):51-54.

43. Nie Q, Lin J. Comparison of intermaxillary tooth size discrepancies among different malocclusion groups. Am J Orthod Dentofacial 
Orthop 1999 Nov;116(5):539-544. DOI: 10.1016/S0889-5406(99) 70186-1.

44. Hashim HA, Murshid Z. Mesiodistal tooth width in a Saudi population: A preliminary report. Saudi Dent J 1992;5:68-72. DOI: 10.4103/22780203.99760.

45. Basaran G, Selek M, et al. Intermaxillary Bolton tooth size discrepancies among different malocclusion groups. Angle Orthod 2006 Jan;76(1):26-30. DOI: 10.1043/0003-3219(2006)076[0026:IBTSD A]2.0.CO;2.

46. Uysal T, Sari $Z$, et al. Intermaxillary tooth size discrepancy and malocclusion: is there a relation? Angle Orthod 2005 Mar;75(2): 208-213. DOI: 10.1043/0003-3219(2005)075<0204:ITSDAM>2.0.CO;2.

47. Murshid Z, Hashim HA. Mesiodistal tooth width in a Saudi population: a preliminary report. Saudi Dent J 1992;5:68-72.

48. Hattab FN, al-Khateeb $S$, et al. Mesiodistal crown diameters of permanent teeth in Jordanians. Arch Oral Biol 1996 Jul;41(7):641-645. DOI: 10.1016/S0003-9969(96)00066-0.

49. Leung EMY, Yang Y, et al. A Comparative Analysis of Tooth Size Discrepancy between Male and Female Subjects Presenting with a
Class I Malocclusion. Scientific World Journal 2018 Jul;2018:7641908. DOI: $10.1155 / 2018 / 7641908$.

50. Ghose LJ, Baghdady VS. Analysis of the Iraqi dentition: mesiodistal crown diameters of permanent teeth. J Dent Res 1979 Mar;58(3): 1047-1054. DOI: 10.1177/00220345790580030301.

51. Cançado RH, Gonçalves Júnior W, et al. Association between Bolton discrepancy and Angle malocclusions. Braz Oral Res 2015;29:1-6. DOI: 10.1590/1807-3107BOR-2015.vol29.0116.

52. Aldrees AM, Al-Shujaa AM, et al. Is arch form influenced by sagittal molar relationship or Bolton tooth-size discrepancy? BMC Oral Health 2015 Jun;15:70. DOI: 10.1186/s12903-015-0062-2.

53. Akyalçin S, Doğan S, et al. Bolton tooth size discrepancies in skeletal Class I individuals presenting with different dental angle classifications. Angle Orthod 2006 Jul;76(4):637-643. DOI: 10.1043/0003-3219(2006)076[0637:BTSDIS]2.0.CO;2.

54. Johe RS, Steinhart T, et al. Intermaxillary tooth-size discrepancies in different sexes, malocclusion groups, and ethnicities. Am J Orthod Dentofacial Orthop 2010 Nov;138(5):599-607. DOI: 10.1016/ j.ajodo.2008.11.031. 